\title{
UN EGOÍSTA COLECTIVO. ENSAYO SOBRE EL INDIVIDUALISMO SEGÚN GAUTHIER
}

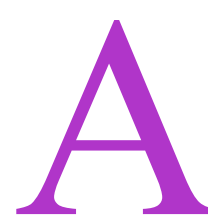

sistimos hoy como actores y espectadores a las transformaciones de la sociedad contemporánea. Por una parte, el idílico racionalismo naturalista de la mano invisible guiado por el autointerés se estrella frente a la racionalidad colectiva representada por el Dilema del Prisionero: el individuo egoísta smithiano es irracional -no maximiza sus beneficios- desde el punto de vista de la racionalidad colectiva.

Por otra parte, y como consecuencia de ello, el Estado introduce mecanismos correctores del mercado porque éste es incapaz de comportarse eficientemente en todos los ámbitos. Sus quiebras están a la orden del día y su descripción es objeto de regocijo por parte de los estudiosos. El lenguaje de los parásitos, informaciones asimétricas, riesgos morales lo pone de manifiesto. El mercado continúa funcionando pero muy presionado desde arriba y desde abajo. Desde arriba porque el Estado toma decisiones que cercenan el ámbito del mercado. Pero el fenómeno no deja de ser paradójico porque al mismo tiempo la decisión estatal se diluye merced a la multiplicación de administraciones sea la comunitaria, la estatal o la autonómica. Desde abajo, el mercado se ve limitado por el proceso de concentración empresarial. Poco a poco el mundo económico y social convierten los esquemas tradicionales en inadecuados. Al mercado ya no acuden individuos aislados más o menos iguales, sino potentes organizaciones.

Hoy más que nunca somos conscientes de los innumerables problemas que originan los mercados. Nuestro mundo no es smithiano y la mano invisible no nos conduce a los resultados previstos. En este mundo todos usamos los lavabos pero la mano invisible produce como externalidad lagos y ríos deteriorados. Las externalidades y las ineficacias del mercado exigen la

* Me he beneficiado de las críticas y comentarios de M. Atienza, E. Garzón Valdés, J. Malem y R. Zimmerling para la redacción de este trabajo. 
intervención del Estado. El problema de la justificación de los bienes colectivos se replantea.

Políticos y funcionarios toman decisiones que responden a criterios institucionales sobre el bienestar colectivo. La vida social y económica depende de aquéllas. Ello supone una concepción supraindividualista, una concepción del bien superior a los individuos. Desde el Estado se diseña una concepción de la justicia y del bien común que el mercado es incapaz de generar. La principal consecuencia de ello es que los intereses de los individuos y de la colectividad no responden a los mismos criterios. La racionalidad individual y la colectiva se presentan como contradictorias.

El Estado, a pesar de ser intervencionista, no renuncia por ello a su pretensión liberal individualista. Nuestra concepción compartida de la justicia no implica la subordinación absoluta del individuo a la colectividad. El estado social y democrático de derecho se toma a los individuos en serio.

Explicar la crisis de la moral desde esta perspectiva puede resultar aleccionador. El equilibrio entre bienes colectivos y valores individuales -constantemente desequilibrado por las tensiones y relaciones inversas entre racionalidad individual y colectiva- no se ha alcanzado. La obra de Gauthier se produce en este contexto y representa uno de los intentos más acabados de unificar la racionalidad individual y la colectiva, los valores liberales y la actividad intervencionista correctora de las ineficiencias e injusticias del mercado. Sostiene que las restricciones que establece la moral en el mundo real interesan a los individuos racionales y egoístas. Para ser racional se debe cumplir con la moral.

Morals By Agreement constituye una respuesta interesante a la crisis de la Moral. Gauthier se enfrenta a la tradición dominante del pensamiento occidental que considera que el núcleo de la moral consiste en establecer restricciones a los intereses de los individuos. $\mathrm{Su}$ gran proyecto consiste en reconciliar la racionalidad con la moralidad.

Ahora bien, el concepto de racionalidad tiene una pluralidad de significaciones. ¿En qué sentido lo utiliza? Gauthier parte de la económica y presupone que el hombre es egoísta y que persigue sus propios intereses ${ }^{1}$. El individuo racional trata de maximizar

${ }^{1}$ Gauthier sostiene reiteradamente en Morals by Agreement (a partir de ahora citado por $M$. A.), Oxford University Press, 1986 el concepto de racionalidad ligado con el de maximización. Por ejemplo, en la pág. 6 dice: «una persona actúa racionalmente si y sólo si busca su mayor beneficio o interés». 
sus beneficios. La filosofía de Gauthier parte del autointerés y la entiende como el acuerdo sobre las restricciones necesarias para preservar y mejorar los intereses individuales en unas circunstancias que mejoran la situación del hombre económico ${ }^{2}$. Uno de los argumentos más importantes de este autor es que el hombre económico deja de percibir beneficios que podría obtener si estableciera mecanismos de cooperación. El hombre gauthieriano está impregnado de la filosofía del hombre racional económico ${ }^{3}$ pero lo supera por la vía del egoísmo y no del altruismo. Esta es una de sus pretensiones ${ }^{4}$ : argumentar que los criterios que el hombre debe respetar en situaciones de racionalidad colectiva son más ventajosos para sus intereses que la maximización estricta. Y estos criterios constituyen la moral por acuerdo.

Una de las aportaciones más interesante de Gauthier es la utilización del instrumental analítico de la teoría de la elección racional para el estudio de la moralidad5. Concretamente, la moral por acuerdo es -según Gauthier- una de las partes más

En la pág. 22 «la racionalidad práctica en su sentido más general se identifica con la maximización de los beneficios». Para la crítica de la obra de Gauthier véase E. Frankel Paul y otros (eds.), The New Social Contract. Essays on Gauthier. Oxford Basic Blackwell, 1988. Véase también J. Coleman, Markets, Morals and the Law, Cambridge University Press, 1988, especialmente el capítulo 13.

${ }^{2}$ «Nuestra teoría rechaza cualquier restricción racional... que no conlleve un beneficio mutuo. Una teoría contractualista de la moral no da ningún valor a las obligaciones meramente redistributivas que transfieren bienes de unos a otros, pero no generan beneficios mutuos.» Pág. 16 de $M$. $A$.

${ }^{3}$ Véase $M$. A., pág. 182, en la que afirma que una elección es racional si y sólo si maximiza la utilidad esperada del actor.

${ }^{4}$ El concepto de racionalidad es muy ambiguo. Véase sobre los diversos conceptos de racionalidad J. Elster, Uvas amargas, Barcelona Península, 1988, cap. I. Aquí lo utilizaremos en el sentido de racionalidad económica. Pero después veremos que la interpretación recibida de los economistas -el maximizador estricto de beneficios- es reinterpretada conforme a unos principios diferentes y Gauthier reconstruye un modelo de individuo liberal distinto al hombre económico que denominaremos el hombre gauthieriano.

${ }^{5}$ En la pág. 2 y sig. afirma: «Desarrollaremos una teoría moral como parte de la teoría de la elección racional. Argumentaremos que los principios racionales para tomar decisiones entre acciones posibles incluyen algunas que limitan la persecución del autointerés de un modo imparcial. Estas limitaciones las identificamos como principios morales.» En la pág. 4 afirma que «se puede suponer que la teoría de la elección racional y la teoría moral sólo están relacionadas porque poseen una estructura similar. Pero, nosotros desarrollaremos la teoría moral como una parte importante de la elección racional». Y más adelante, en pág. 5, afirma mostrando sus diferencias con Harsany que «un individuo debe elegir moralmente para elegir racionalmente». 
importantes de la teoría de la elección racional ${ }^{6}$. El imperialismo de la teoría de la elección racional ha integrado partes muy sustanciales de la teoría económica, de la filosofía moral y de la ciencia política. En este sentido, la obra de Gauthier pretende colaborar a la unificación de la Ciencia Social.

Otra perspectiva importante a tener en cuenta es el aspecto normativo de su teoría. Nuestra teoría -dice Gauthier en M. A., pág. 2- «provee una justificación -y no una explicación- de los principios y de la conducta moral. Desarrollaremos una teoría normativa de la moral». Es por tanto una teoría que pretende dar razones que justifican la adopción de ciertos principios morales.

Pero mi preocupación en este trabajo no es llevar a cabo una valoración global de la obra de Gauthier, sino analizar algunos aspectos relevantes de su concepción del hombre y su relación con la racionalidad. El hilo conductor partirá del análisis del concepto de racionalidad económica admitido por Gauthier. Luego estudiaré el modelo de hombre gauthieriano y por qué no coincide con el económico. Indicaré cuáles son los argumentos que permiten mostrar la superioridad de un modelo sobre otro -en un contexto de racionalidad colectiva- desde el punto de vista del egoísmo y, para acabar, analizaré hasta qué punto la empresa gauthieriana tiene éxito en la elaboración de su modelo de hombre y de su moralidad. Argumentaré que la moral no se puede fundamentar únicamente en el egoísmo. Ni Hobbes ni Gauthier pueden prescindir de ciertos principios normativos fundamentales externos y distintos al autointerés.

\section{El concepto de racionalidad}

Empecemos por el concepto de racionalidad. Es bien sabido que la racionalidad se atribuye a multiplicidad de entidades, como por ejemplo, preferencias, elecciones, instituciones, acciones y decisiones. Gauthier parte del hombre económico y sostiene que el hombre es racional si trata de satisfacer sus preferencias meditadas. El hombre económico es egoísta y sólo tiene en cuenta sus intereses. No es altruista ni tiene en cuenta los intereses de los demás. El primer punto importante es la reducción de

${ }^{6}$ Véase $M . A$., pág. 5 y sig. para la relación entre Teoría de la elección racional y teoría moral.

${ }^{7}$ Véase $M$. A., págs. 23 y sigs. para la definición y propiedades de las preferencias meditadas. 
la racionalidad a racionalidad económica. Desde este presupuesto se plantea si es posible la emergencia de una moralidad y si esa moral siempre establece restricciones a los intereses egoístas y es por tanto un elemento externo a los individuos.

La doctrina ético-política dominante en la historia enseña que la moral es un conjunto de restricciones de los intereses individuales. Si eso es cierto, entonces es imposible reconciliar la moral con la racionalidad. La moral es algo ajeno al sujeto, que se le impone desde fuera. Griffin ha denominado a este problema el de la alienación de la moral ${ }^{8}$. Gauthier trata de avanzar en el análisis de este problema preguntándose cómo es posible superar la contradicción entre moralidad y racionalidad. Si la empresa gauthieriana tuviera éxito entonces se habría dado un gran paso para resolver el problema de la alienación de la moral porque entre el autointerés y la moral no se darían conflictos. Como más adelante veremos, Gauthier pretende responder la objeción del tonto (fool) del Leviathan criticando la relación entre racionalidad e interés individual establecida por Hobbes en el tema del cumplimiento de los pactos ${ }^{9}$.

\section{La hipótesis del mercado ideal}

Dando por supuesta la antropología racionalista del hombre económico, la moral carece de sentido en condiciones de mercado ideal. El egoísmo individual guiado por la mano invisible conduce al resultado de un óptimo de Pareto. Cualquier restricción de los intereses egoístas conduce a un resultado subóptimo de Pareto. Si eso es cierto, entonces la reconciliación entre la racionalidad y la moralidad es imposible. Y ése es el caso en las condiciones del mercado ideal.

Gauthier sostiene que en esta situación no existe espacio para la moral porque cualquier restricción establecida por la moral supondría una irracionalidad, es decir, un subóptimo de Pareto. En un mercado ideal, el equilibrio es un óptimo de Pareto y eso produce o la identificación entre racionalidad y moralidad o una zona libre de moral. Si la moral debe tener algo que ver con la racionalidad en ese caso o no hay espacio para la moral porque cualquier restricción moral supone un subóptimo de Pareto y

${ }^{8}$ Véase J. Griffin, Well-being, Oxford, Clarendon Press, 1986, págs. 127 y sigs.

${ }^{9}$ Gauthier explica las relaciones de su teoría con la de Hobbes en la pág. 10. Las principales discrepancias pueden verse en las págs. 158 y sigs. 
por tanto la moral es irracional o bien moralidad y racionalidad se confunden ${ }^{10}$. Ambas prescriben lo mismo: la maximización de beneficios. Gauthier es explícito en este punto, pues llega a afirmar que «el mercado y la moral reconcilian de un modo no coercitivo el interés individual y el beneficio mutuo» (pág. 14).

\section{La hipótesis del mundo real}

Sin embargo, el mundo real no es el mundo ideal. En el mundo real existen numerosas rupturas del mercado. Los casos del parásito y del free rider, muestran que en situaciones reales la defensa de intereses individuales a través de los mecanismos de mercado produce subóptimos de Pareto. Es precisamente por esta razón que Gauthier busca construir una moral fundamentada en el autointerés y que encuentra su brecha en las quiebras del mercado. En el mundo real la racionalidad individual fracasa en la generación de bienes públicos. Es necesario introducir criterios restrictivos del egoísmo individual para que alcance los resultados de la racionalidad colectiva.

Por esa brecha tratará de conquistar la montaña de la moralidad -entendida como restricciones del autointerés pero que tienen como consecuencia un surplus beneficioso para el propio individuo- utilizando unas herramientas muy sofisticadas como la teoría de la elección racional, la del maximizador constreñido, las cláusulas cautelares de no dañar al otro ni explotarlo, la idea de la estabilidad, la idea de la igual racionalidad de los hombres, el principio de imparcialidad y una teoría de la negociación determinada. Pero no abandona el concepto de racionalidad. El intento de Gauthier de construir una moral por acuerdo se basa en el autointerés. Racionalidad y Moralidad no son incompatibles en el mundo real porque los mercados reales no son ideales. Existen situaciones en las que el racionalismo del hombre económico no conduce al óptimo de Pareto. Un buen ejemplo lo encontramos en el Dilema del Prisionero -símbolo de la racionalidad colectiva en el seno de la cual el individuo racional económico fracasa estrepitosamente- en los casos de información asimétrica o en la generación de los bienes públicos.

Gauthier es un defensor de la economía de libre mercado aunque reconoce sus limitaciones en el mundo real, ya que los bienes públicos se ofrecen a través de un procedimiento ineficiente

${ }^{10}$ Véase $M$. A., pág. 13. 
e injusto. Más que suprimir el mercado lo que se necesita es complementarlo con instituciones y prácticas cooperadoras que aseguren una oferta de bienes públicos óptima.

Su propuesta es análoga a la teoría del hombre económico porque cree en el modelo ideal de la mano invisible, pero en caso de quiebra del mercado -el caso del parásito o del polizón- una mano visible debe enmendar las imperfecciones (M. A., pág. 113). Esa mano visible debe diseñar instituciones o prácticas cooperativas para que el hombre económico se vea superado por el hombre gauthieriano. Obsérvese que el individualismo económico de Gauthier no supone cerrarse al diseño de instituciones que permitan superar el hombre económico. Su gran desafío consiste en superar el hombre económico sin perder algunas de sus propiedades esenciales como, por ejemplo, el individualismo, el racionalismo económico y el egoísmo. Pero esas propiedades deben cambiar en un contexto de racionalidad colectiva. Para ser racional no se puede ser un maximizador estricto.

Pero Gauthier es liberal en otro sentido más fuerte si cabe: es subjetivista e individualista. No existe ningún valor de justicia por encima de las preferencias de los individuos. El ideal de autonomía y de la dignidad de la persona ocupa un lugar muy importante. El individualismo constituye un valor sustancial. Su diseño de una sociedad justa no responde a una idea supraindividual. En este punto Gauthier es explícito: «Nuestro objetivo es demostrar la posibilidad y las características de una moral racional dando por supuesto que el valor es subjetivo y relativo» (M. A., pág. 59). La moral puede consistir en un conjunto de procedimientos y de restricciones para que sea posible y mutuamente beneficiosa la cooperación. Gauthier afirma que «podemos esperar cierto grado de conflicto entre los intereses y deseos individuales y la armonía natural. El mercado y la moral amansan estos conflictos reconciliando la individualidad con el beneficio mutuo» (M. A., pág. 19). Pero en ningún caso «un individuo debe sacrificar su propio interés en favor de otros con el objetivo de conseguir la satisfacción de la relación social» (M. A., pág. 351).

La moral gauthieriana no crea un concepto sustantivo de justicia impuesto desde fuera por un sabio o por un profeta o por el Estado. Este punto es muy importante porque pretende salvaguardar un núcleo importante de la filosofía liberal. La sociedad debe ser diseñada de tal forma que permita el máximo desarrollo de las capacidades y preferencias de los individuos. La moral por acuerdo es el instrumento que permite ampliar y profundizar las preferencias de los individuos. Pero lo primario, lo que se debe 
preservar, lo que es valioso es la autonomía del individuo que se manifiesta en sus preferencias meditadas. Por esa razón su teoría es liberal individualista: «Lo que es bueno lo es porque es preferible y únicamente es bueno para los que lo prefieren ${ }^{11}$.

Pero para defender su tesis necesita responder a dos cuestiones:

— La primera hace referencia a cuál es el contenido de esta moral por acuerdo, sin coacción ni imposiciones externas. La moral gauthieriana es la del autointerés. La crisis de la moral se manifiesta porque ser inmoral o amoral es más beneficioso que ser moral como reza la célebre tesis de Glaucón. Gauthier reacciona frente a esta tesis y sostiene que ser moral es más beneficioso para los intereses individuales que no serlo. El individuo tiene primacía sobre la sociedad pero le conviene cooperar. Y le conviene porque de esta forma se asegura más posibilidades de beneficio que si no está dispuesto. Gauthier afirma que «los maximizadores moderados son capaces de hacer acuerdos beneficiosos con sus compañeros mientras que los estrictos no ... porque no serán aceptados por los demás dada su disposición a violar los pactos» (M. A., pág. 173).

- La segunda cuestión hace referencia a los motivos que tienen los hombres para abrazar una concepción de la moral por acuerdo. Y eso supone también un tipo de hombre distinto al hombre económico maximizador de sus intereses pero incapaz de cooperación por miedo a la explotación. Gauthier sostiene que el hombre que defiende sus intereses egoístas no puede alcanzar todos los valores porque hay algunos fines que sólo se pueden alcanzar mediante la cooperación.

\section{El hombre económico y el gauthieriano}

El hombre económico y el gauthieriano -aunque son distintos- tienen unos puntos de coincidencia (M. A., pág. 346): Primero, los dos maximizan sus preferencias y sus utilidades (que son las medidas de sus preferencias). Segundo, los dos se caracterizan porque siempre quieren más, es decir, son insaciables. Tercero, los dos son, en cierta medida, asociales en el sentido de que persiguen sus propios intereses y no actúan por benevolencia

\footnotetext{
${ }^{11}$ Véase sobre este punto del subjetivismo y el relativismo la pág. 59 de $M . A$.
} 
o por razones altruistas. La moral por acuerdo capta el sentido general del hombre económico pero fabrica un hombre distinto. El hombre económico y el gauthieriano no son idénticos. Gauthier sostiene que si respetamos el sentido general del hombre racional ideal, y si lo trasplantamos al mundo real, y sostenemos al mismo tiempo los principios generales del individualismo liberal, el hombre racional no puede ser el hombre económico sino el gauthieriano porque ha aprendido del fracaso estrepitoso del hombre económico en situaciones de racionalidad colectiva representada por el Dilema del Prisionero. La cooperación -por tanto- no emerge del altruismo sino del egoísmo. Si el hombre persigue sus propios intereses -en un mundo en el cual las decisiones de unos interfieren en las decisiones de otros- le conviene más cooperar que dejar de hacerlo.

El hombre gauthieriano es social no porque considere que existe una instancia superior que le obligue a ser altruista sino que es social porque le conviene. Ser egoísta supone también beneficiarse de la posibilidad de la cooperación. En este sentido el liberal individualista gauthieriano es distinto al hombre económico. Allí donde éste no es racional -por ejemplo en los bienes públicos- el gauthieriano lo será. Este desea cooperar porque es consciente de sus limitaciones. La escasez le conduce a comportarse de modo cooperativo. Pero la escasez puede ser de muy diversos tipos. Las utopías acostumbran a crear modelos de sistemas económicos sin escasez. Pero el mundo real no es un mundo utópico. Y eso el hombre gauthieriano lo sabe. Tiene incentivos para comportarse cooperativamente.

\section{Un rodeo por la escasez, la utopía y los ideales cooperativos}

Gauthier estudia la utopía para mostrar que la escasez es el motor de la cooperación. El hombre gauthieriano no es autosuficiente porque hay valores que él mismo persigue y sólo puede conseguir mediante la cooperación. El rodeo a través del análisis de la Utopía (M. A., págs. 330 y sigs.) le sirve para plantear algunos problemas importantes. La Utopía supone el fin de la escasez. Muchas veces cuando se piensa en la utopía se cree que los recursos se asignan de tal forma que se producen suficientes riquezas para todos y por tanto en la Utopía la distribución deja de ser problema. Sin recursos escasos la justicia distributiva no existe.

Gauthier sugiere que las utopías son entelequias y mitos porque aun en el hipotético caso de que llegáramos a la situación de 
producir suficientes bienes para todos, aun en el caso de que no se plantearan problemas de distribución, siempre existirían problemas de escasez, de tiempo, conocimiento e información. La utopía marxista sólo se plantea el problema de la producción y parece que una vez que se hayan liberado las fuerzas productivas las riquezas manarán como ríos de las montañas y, por lo tanto, cualquier forma de vida será accesible al hombre.

La tesis de Marx -según Gauthier- es unilateral porque aunque careciésemos de limitaciones a la hora de escoger entre productos y pudiéramos elegir cualquiera de ellos, el consumo siempre será limitado. Cualquier forma de vida no es accesible a cualquier hombre. Quizá es posible que en una sociedad primitiva a las nueve uno sea pescador, a las doce carpintero y a las tres agricultor. Pero esa no es la vida del siglo XX. Nadie en una sociedad desarrollada puede ser a las nueve pianista, a las doce cirujano, a las cuatro programador de informática y a las ocho ciclista profesional. Para disfrutar de ciertos bienes es necesario sostener la división social del trabajo. Sin división y especialización no es posible alcanzar objetivos en una sociedad postindustrial. De nuevo nos encontramos con los planteamientos individualistas economicistas. Smith celebraba la división social del trabajo porque permitía aumentar la productividad y favorecía el intercambio.

La escasez no sólo es de producción sino que lo es también de conocimiento y de consumo (M. A., págs. 334 y sigs.). Aquellos que valoran la cooperación -argumenta Gauthier en pág. 337- consideran que una moralidad por acuerdo, «además de ser una fuente de restricciones convierte su actividad mutua en estable y bien recibida porque asegura la ausencia de coacción».

Pero existen otros argumentos:

1. Los hombres sólo tienen una vida. Elegir significa asignar el tiempo que necesariamente es escaso. Decidirse en favor de una cosa excluye otra.

2. Los hombres no sólo tienen ideales individuales sino ideales cooperativos que necesitan de una cierta especialización, división del trabajo y conocimiento específico. Un buen ejemplo es el caso de quien desea ser futbolista o clarinetista de una orquesta. Precisamente de la limitación de los individuos y de la insuficiencia individual surge y emerge la cooperación para alcanzar objetivos que sólo cooperando se pueden obtener. Sólo si existen varios jugadores puede jugarse al fútbol o sólo si existen instrumentistas se puede organizar una orquesta. Gauthier está muy interesado en mostrar que si el hombre persigue su propio 
interés debe abrazar voluntariamente la Moral por acuerdo porque puede alcanzar fines superiores (o que el hombre calibre superiores a los que podría alcanzar por sí solo). Por eso el gauthieriano no es el hombre económico ni tampoco es un colectivista que considera que la sociedad tiene valores sustantivos superiores e independientes de las preferencias de los individuos. Gauthier ha hecho una incursión por el mundo de la utopía para poner de manifiesto las limitaciones del hombre económico.

El hombre gauthieriano es consciente de la escasez y sabe cuáles son sus limitaciones, y que la única forma de conseguir ciertos ideales individuales es mediante la cooperación. Pero es semejante al hombre económico porque es un ser activo y encuentra satisfacción en la actividad. Tiene su propia concepción del bien pero no es asocial. Es un ser autónomo que valora la sociedad porque le conviene. Es racional porque tiene capacidad para elegir y perseguir sus objetivos y fines maximizando su utilidad esperada.

Ahora bien, es un hombre distinto al económico porque sabe que la riqueza de sus decisiones depende de la existencia y de las elecciones de otras personas por esa razón valora positivamente tanto la participación como a los individuos que participan. Valora también las limitaciones que hacen posible la participación.

Con estos argumentos Gauthier nos ha fabricado un modelo de hombre que es capaz de dar el salto de la cooperación sin necesidad de la coacción. En este punto se separa de Hobbes y Locke y trata de lograr el mismo objetivo -la cooperación- por el camino de la moralidad. La moral por acuerdo constituye una respuesta distinta al problema que se planteaba Hobbes con el contrato social. Mientras la respuesta política supone la creación de un aparato coactivo o de una magistratura, en el caso de Gauthier la coacción se ve sustituida por la racionalidad y el acuerdo (M. A., pág. 268).

Si observamos las limitaciones de los individuos y los beneficios que se generan en la participación entonces no será necesaria la coacción porque los individuos que persiguen sus propios intereses -y son plenamente conscientes de ello- están más interesados en cooperar que en no hacerlo. El hombre económico maximiza sus beneficios individuales pero renuncia a la participación y quizá renuncia a asignar sus recursos y su tiempo de la forma óptima porque no podrá conseguir los bienes que sólo se pueden alcanzar mediante la cooperación. El hombre económico no consigue el óptimo de Pareto en las condiciones de mercado 
real, mientras que el gauthieriano sí. Este es el gran argumento de Gauthier. En M. A., pág. 183, sostiene que «un maximizador absoluto que está dispuesto a hacer elecciones maximizadoras debe esperar ser excluido de los acuerdos cooperadores en los cuales encontraría ventajas. Un maximizador limitado debe esperar ser incluido en estos acuerdos ... Defendemos la racionalidad de los maximizadores limitados ... En situaciones de elección estratégica la disposición a hacer elecciones maximizadoras limitadas es maximizadora de la utilidad».

El hombre de Gauthier está dispuesto a cooperar y no ser un maximizador de beneficios estricto sino limitado. Está dispuesto a ofrecer concesiones siempre y cuando el surplus de la cooperación le ofrezca suficiente compensación porque el resultado global de la cooperación es superior al resultado producido sin cooperación.

Ahora bien, ¿cómo se consigue que el hombre actúe de este modo? Gauthier sostiene que una persona valora la cooperación en función del valor que atribuye al fin en relación a los costes que debe pagar para conseguirlo. Si cada participante encuentra fines intrínsecamente valiosos estará dispuesto y será sensible a la cooperación. Los individuos se interesan en la cooperación cuando no ven a los otros como explotadores, ya que no quieren sacar ventaja el uno del otro sino únicamente de la cooperación.

Pero ¿cómo sabemos quién está dispuesto a cooperar, es decir, quién no es un maximizador estricto? Gauthier introduce los conceptos de hombres transparentes, opacos y traslúcidos. Sostiene que el transparente muestra claramente su disposición o no a la cooperación; el opaco no da ninguna pista para conocer su disposición a la cooperación y el traslúcido ofrece suficiente información para conocer si tiene o no la disposición para la cooperación. El hombre gauthieriano es traslúcido. Evidentemente si fuera transparente podría distinguir entre el maximizador estricto y moderado y sabría con quién ha de cooperar pero eso supondría considerar la sociedad de los hombres como una sociedad de ángeles. Despojaría -por tanto- a la teoría de toda aplicación práctica. Como bien dice Gauthier en M. A., pág. 174: «Asumir la transparencia despoja a nuestro argumento de interés. Queremos relacionar nuestras asunciones ideales con el mundo real. Si el maximizador moderado sólo derrota al absoluto si se supone que todas las personas son transparentes habremos fracasado en mostrar que las personas actuales y en condiciones reales son racionales si aceptan las restricciones morales». La idea de traslúcido supone que la disposición o no para 
la cooperación puede ser afirmada no con certeza sino con algo más que con meras conjeturas (M. A., pág. 174).

En síntesis, Gauthier sostiene que su modelo es superior al económico porque genera más beneficios. Por tanto, será racional (conveniente desde el punto de vista de sus intereses) abrazar el ideal de la moralidad por acuerdo y por tanto no existirá incompatibilidad entre Racionalidad y Moralidad.

$\mathrm{Si}$ nos preguntamos por las razones que tienen los individuos para aceptar esta moral, la respuesta es muy sencilla: es más beneficiosa para el propio individuo que el egoísmo económico. Por tanto, si el hombre es plenamente racional las restricciones que establezca la moral serán adoptadas voluntariamente sin necesidad de coacción y se superará el problema de la alienación de la moral.

Pero ¿cuál es el contenido de esta moral?

En este punto el liberalismo individualista de Gauthier es riguroso. El holismo siempre ha sostenido que una sociedad justa supone un contenido determinado del bien común. Gauthier se enfrenta al colectivismo, al socialismo y a todas aquellas teorías sociales que no respetan la autonomía y la individualidad y les imponen desde fuera los criterios de justicia. Se enfrenta a todas las concepciones artificiales de la justicia según las cuales una elite, un sabio o un conjunto de personas están mejor calificadas que los individuos para definir qué es lo justo o lo bueno. Es una moral contraria a cualquier forma de fundamentalismo. Sostiene, por tanto, otra tesis defendida por el liberalismo más tradicional. La incompatibilidad entre valores -holísticos y supraindividuales- objetivos sociales impuestos por alguien y los derechos y la autonomía individual. Gauthier insiste en el individualismo liberal, pues una sociedad liberal no tiene objetivos sustanciales justos ( $M$. $A$., pág. 341). No existen valores superiores a los que los propios individuos tienen como tales. Supone, por tanto, el respeto de la autonomía del individuo. La estructura de la sociedad incentiva y garantiza el orden social en el cual se desarrollan las iniciativas de los individuos. El elemento primario es la preferencia meditada del individuo. La sociedad es un instrumento para la realización de objetivos individuales. La sociedad sólo constituye un cinturón protector de seguridad para que los individuos desarrollen libremente sus iniciativas. Una sociedad es justa si «permite que cada persona persiga su mayor bien posible en términos que sean aceptables para todos» (M. A., pág. 341). 
Una sociedad justa respeta la autonomía de las personas y es compatible con la racionalidad reflexiva de los individuos (M. A., pág. 341). Es decir, supone la posibilidad de la definición y del cambio de preferencias de los individuos en el tiempo.

El hombre gauthieriano no defiende una concepción del bien objetivo e impuesto desde fuera (M. A., pág. 349). Una buena sociedad ha de permitir y tolerar la existencia de distintas preferencias. No sólo eso, sino que una sociedad que se rija por este principio es más rica y hace posible y rentable la cooperación (M. A., pág. 337). Del mismo modo que la división del trabajo no es una limitación, sino una ventaja, una sociedad organizada de tal modo que incentive y tolere diversas concepciones de vida y preferencias es una sociedad justa.

Pero si el individuo tiene prioridad sobre la sociedad, entonces la socialización para la ventaja mutua ¿tiene sentido o es contradictoria? La función de la socialización es conseguir las ventajas que los individuos autónomos no podrían conseguir por sí solos. La insuficiencia individual tanto en la producción de bienes como en el de la realización de planes de vida se disminuye gracias a esta socialización. Y el individuo cuando reconoce esta necesidad abraza la moral por acuerdo sin que sea necesaria ninguna coacción.

Gauthier concluye sosteniendo y apuntalando las tesis sustanciales de la moral por acuerdo con la imagen del hombre gauthieriano. No pone en duda que el progreso de Occidente se debe en gran medida al individualismo liberal que ha potenciado al máximo las capacidades humanas. «Históricamente, la individualidad ha surgido -tanto prácticamente como conceptualmente- en un entorno en el cual ha existido una fuerte correlación entre la persecución del interés individual y la provisión de bienes y servicios» (M. A., pág. 354).

La emergencia de una moral por acuerdo supone un fundamento racional y egoísta. La moral no está constituida por un conjunto de restricciones irracionales, sino que son aquellas restricciones que permiten potenciar al máximo las capacidades y los intereses de los individuos. Cuando el hombre se percata de los beneficios de las restricciones establecidas entonces elige la moral por acuerdo y ya no considera incompatible racionalidad y moralidad.

\section{Reflexiones críticas finales}

1. Cualquier doctrina contractualista parte de una situación original en el estado de naturaleza y exige por las razones que 
sean -la inseguridad, la racionalidad, la prudencia, etc.-, salir de la vida natural. En algunas doctrinas existe ignorancia, en otras existe conocimiento e información suficiente. El caso de la de Gauthier el hombre no sólo tiene información sino que es capaz de contratar y llegar a un acuerdo siempre y cuando la estructura de la interacción sea suficientemente beneficiosa para el propio individuo. Los ideales de justicia son individuales, ya que no hay una concepción sustantiva de la justicia social que se pueda imponer desde fuera a los individuos.

Sin embargo, según el propio Gauthier el desarrollo pleno de la autonomía humana sólo se puede conseguir en la sociedad. Hay ideales individuales alcanzables mediante la cooperación y la sociedad sería un instrumento de la cooperación. Si se admite este paso, entonces parece que la realización plena de la autonomía del individuo sólo se encuentra en el marco de un cierto tipo de sociedad y para lograr ese objetivo deberá preservarse esa sociedad. El individualismo liberal de Gauthier es muy moderado porque reconoce que el hombre sólo puede conseguir el pleno desarrollo de sus capacidades en la sociedad. Y posiblemente si eso es cierto entonces deberá estar obligado a mantener una sociedad que permite al hombre ser autónomo. Fuera de la sociedad la autonomía es muy limitada. ¿No desemboca el individualismo en unas obligaciones impuestas desde fuera? O bien, ¿debemos pensar que el individualismo de Gauthier no es autosuficiente? En otras palabras, ¿no requerirá la autonomía plena del individuo una protección y una defensa adecuada de la sociedad? El egoísta colectivo gauthieriano tiene interés en asumir y defender determinada estructura de la sociedad.

2. El modelo de hombre gauthieriano sólo funciona si es traslúcido. Gauthier insiste en que su modelo se fundamenta en la propiedad de comunicar su disposición o no a la cooperación. El hombre gauthieriano no es transparente porque no se conoce con seguridad su disposición o no a la cooperación. Ahora bien, ¿como descubrimos esta característica? Gauthier sostiene que si el individuo es traslúcido -es decir, si conocemos con algo más que meras conjeturas su disposición o no a la cooperación- cooperará incluso en la situación del dilema del prisionero no reiterado. En la vida real no está claro cuándo nos encontramos frente a un sujeto traslúcido. En casos del Dilema del Prisionero reiterado existen algunos procedimientos pero en el caso de Gauthier la cooperación debe existir incluso cuando no existe esperanza de futuras relaciones.

De cooperador transparente conocemos lo que va a hacer. Pero Gauthier no toma en cuenta esta idea porque no se cumple 
en la práctica. Muchos individuos no son transparentes. Además el transparente es fácilmente explotable en una sociedad de egoístas racionales estrictos.

Del cooperador traslúcido sólo tenemos algo más que conjeturas sobre su disposición a la cooperación pero no es algo claro. Por tanto, sólo se puede descubrir calculando la probabilidad. ¿Pero cómo calcularemos la probabilidad si la situación de interacción sólo se da una vez? Sólo si sabemos que la mayoría de los ciudadanos están dispuestos a cooperar tendríamos las ventajas probabilísticas de la cooperación. Pero es muy posible que se interaccione con personas -de las cuales no conocemos su disposición a la cooperación- y entonces el liberal gauthieriano sale perdiendo y si pierde tenderá a convertirse en un hombre racional económico. El concepto de traslúcido es fundamental para distinguir el hombre gauthieriano del económico pero sus líneas de demarcación son muy confusas y eso le invalida para que sea útil en la práctica.

3. ¿Hasta qué punto el problema de la alienación de la moral queda resuelto en la obra de Gauthier?

El concepto originario de racionalidad de Gauthier es muy estrecho y hace difícil la reconstrucción de la cantidad de problemas que se presentan a la moral. Uno puede preguntarse si el autointerés es el único motor que conduce a la moral por acuerdo. Existen algunos conceptos interesantes como el de cláusulas cautelares -que prohíben beneficiarse uno mismo dañando a los otros- que no provienen estrictamente del autointerés, sino que son condiciones para que se pueda producir el acuerdo (M. A., pág. 16). Introduce el criterio de la inestabilidad para aquellas negociaciones que partan de una situación coactiva o que sigan un procedimiento que no respete la imparcialidad, lo cual constituye un límite a la negociación (M. A., pág. 16). También introduce el principio de igual racionalidad de las personas (M. A., pág. 17).

Poco a poco todas y cada una de estas cláusulas y limitaciones van diluyendo aspectos importantes de su doctrina hasta el punto que uno puede preguntarse si con esas excursiones normativas no se ha reducido el papel del autointerés a un aspecto secundario de la doctrina. De una forma gradual e imperceptible se introduce un «mordisco normativo» -como diría Garzón Valdés- que proviene de instancias distintas del autointerés. Si reconstruyéramos este mordisco nos encontraríamos con elementos sustanciales de lo que se denomina la dignidad o la autonomía de la persona. Por supuesto que en ese caso el problema de la alienación queda pendiente de resolución. Y en la 
medida en que estas limitaciones normativas no proceden del autointerés su proyecto de reconciliar moralidad y racionalidad quedaría por alcanzar.

4. Uno se pregunta si esa moral que debe aceptarse por acuerdo es una moral que excluye a todas las personas que no pueden prestarlo. Nuevos equilibrios dialécticos serán necesarios para incluir a las futuras generaciones o a los niños o dementes. Y de nuevo nos encontramos con el problema de la autonomía y de la dignidad. Un niño, un demente, aunque no puedan prestar su consentimiento son personas y sus derechos merecen protección.

5. También ofrece algunas dudas la calificación de esta teoría como una teoría moral. Seguramente las razones que mueven a la acción son más prudenciales que estrictamente morales. Debemos reconocer que las razones prudenciales pueden ser -a veces- razones para actuar, pero no siempre. Las razones morales tienen la pretensión de ser siempre finales y de vencer a cualesquiera otras. Es posible que existan razones morales para desobedecer el derecho, por ejemplo, pero sería difícil encontrar razones morales para desobedecer la propia moral. Las razones que justifican la desviación o la conculcación de una norma moral son siempre morales o deberían serlo.

Cuando hablamos de moral pensamos también en algo superior a lo que nos conviene. La teoría de Gauthier intenta resolver este problema reduciendo la maximización del beneficio y señalando que lo que a mí me conviene también conviene a los demás. En situaciones de racionalidad colectiva comportarse como un hombre smithiano es irracional y abrazar la moral por acuerdo -es decir, las restricciones al interés- es racional. En el último capítulo de su trabajo señala que quien elija la moral por acuerdo está reflejando no sólo su elección personal sino las posibles preferencias de todos los seres humanos. Decir que eso es una sociedad justa y que por eso se sale del mundo de la prudencia y se pasa al reino de la moralidad es cuanto menos discutible. Quizá otro planteamiento podría ser un poco más profundo. Entre las preferencias de los individuos puede encontrarse el comportarse moralmente como uno de los criterios fundamentales. Si esa preferencia tiene suficiente fuerza social y se impone entonces es el propio individuo el que acepta la moral, pero esos principios morales son distintos a la prudencia, y están por encima de ella en la escala jerárquica de valores.

6. Gauthier parte de presupuestos hobbesianos. La antropología pesimista de Hobbes está en la base de la teoría gauthieriana. Ahora bien, Hobbes no mantiene el egoísmo hasta sus 
últimas consecuencias. Racionalidad y egoísmo van de la mano cuando Hobbes enuncia su primera ley de la naturaleza -la búsqueda de la paz- y la segunda -constituir un pacto social-, sin embargo en la tercera ley de la naturaleza racionalidad y egoísmo se separan. La postura del tonto representa la defensa coherente del autointerés. Hobbes no continúa el argumento y deja sin respuesta el desarrollo coherente del egoísmo: «¿Por qué debemos cumplir los pactos si a veces mi autointerés me lo desaconseja?» (M. A., pág. 15). Gauthier afirma que «la gran debilidad de la teoría contractualista ha sido su explicación defectuosa de la racionalidad del cumplimiento de los pactos» (págs. 161 y sigs.) y pretende ofrecer respuesta al maximizador estricto, a la pregunta no contestada por Hobbes. A partir de aquí se separa de Hobbes y trata de argumentar que la razón y la utilidad van por el mismo camino. El tonto está equivocado en su respuesta pero no en el espíritu. Hobbes separa racionalidad e interés individual. El tonto los une a través del modelo del maximizador absoluto que cuando le conviene no cumple los pactos y explota a los otros. Gauthier trata de reunir el egoísmo, la moralidad y el autointerés a través de su modelo del maximizador limitado. Un análisis detallado de este modelo muestra las dificultades de su aplicación práctica porque depende de la transparencia o traslucidez y del número de individuos dispuestos a cooperar. Gauthier sólo puede dar una respuesta al tonto si además del autointerés introduce algún que otro mordisco normativo como por ejemplo las cláusulas cautelares de carácter lockiano -el no beneficiarse a costa de los otros, no dañarlos ni explotarlos. El precio que paga es el mismo que Hobbes, no generar la moral del autointerés.

7. La propuesta de Gauthier plantea problemas semejantes a los que se planteaban los contractualistas del siglo XVII. Sin embargo, la solución que adopta es distinta. La propuesta de Gauthier tiene un trasfondo anarquista importante porque trata el consenso como el elemento fundamental. En otras palabras, el problema se podría formular del siguiente modo: ¿Acaso se podría lograr el beneficio de una asociación suficientemente amplia sin los sufrimientos de la política? La ciencia política ha respondido negativamente a esta cuestión mediante la instauración del Estado y de la coacción, la moral por acuerdo de Gauthier trata de responder afirmativamente a la cuestión y se acerca al ideal anarquista. La Moral y el Mercado serían instituciones que proveen a la cooperación sin la necesidad de la coacción. 